\title{
Sheets of branched poly(lactic acid) obtained by one step reactive extrusion calendering process: Melt rheology analysis
}

\author{
J. Cailloux ${ }^{1}$, O. O. Santana ${ }^{1}$, E. Franco-Urquiza ${ }^{1}$, J. J. Bou ${ }^{2}$, F. Carrasco ${ }^{3}, J$. Gámez-Pérez $^{4}$, \\ M. L. Maspoch ${ }^{1}$ \\ ${ }^{1}$ Centre Català del Plàstic (CCP) - Universitat Politècnica de Catalunya (UPC), C/ Colom, 114, 08222 Terrassa, Spain \\ ${ }^{2}$ Department of Chemical Engineering - Universitat Politècnica de Catalunya (UPC), Pavelló G, planta 1, Avenida \\ Diagonal,647, 08028 Barcelona, Spain \\ ${ }^{3}$ Department of Chemical Engineering - Universitat de Girona (UdG), Campus Montilivi s/n, 17071 Girona, Spain \\ ${ }^{4}$ Department of Polymers and Advanced Materials - Universitat Jaume I, Avenida de Vicent Sos Baynat s/n, 12071 \\ Castelló de la Plana, Spain
}

Received 4 September 2012; accepted in revised form 28 November 2012

\begin{abstract}
One-step reactive extrusion-calendering process (REX-Calendering) was used in order to obtain sheets of $1 \mathrm{~mm}$ from two PD,L-LA extrusion grades modified with a styrene-acrylic multifunctional oligomeric agent. In a preliminary internal mixer study, torque versus time was monitored in order to determine chain extender ratios and reaction time. Once all parameters were optimized, reactive extrusion experiments were performed.

Independently of the processing method employed, under the same processing conditions, PD,L-LA with the lower D enantiomer molar content revealed a higher reactivity towards the reactive agent, induced by its higher thermal sensitivity. REXCalendering process seemed to minimize the degradations reactions during processing, although a competition between degradation and chain extension/branching reactions took place in both processes. Finally, the rheological characterization revealed a higher degree of modification in the melt rheological behaviour for REX-Calendered samples.
\end{abstract}

Keywords: rheology, poly(lactic acid), chain extender, reactive extrusion, molecular weight distribution

\section{Introduction}

Poly(D,L-Lactide) (PD,L-LA) is well known to be a biodegradable and biocompatible polymer available from renewable resources. In the beginning, it was mainly used for medical applications due to its high fabrication costs but now PD,L-LA polymers have finally found a commercial application in single use disposal items due to its low price compared with other biodegradable polymers. However, its brittle nature reduces its use to very limited applications and its poor melt strength limits specific processes such as film blowing or foaming [1].
As well as many aliphatic polyesters, PD,L-LA is subject to some thermal degradations and instabilities above its melting temperature, especially during processing. Radical and non-radical reactions are proposed to explain the various and complex mechanisms that could occur during processing, leading to a reduction of the molecular weight and viscosity. As a result, a general decrease of the material properties is expected [2].

Several authors $[3,4]$ reported that the residual water or moisture content inside the polymer matrix activates hydrolysis reactions (Figure 1a) implying the

\footnotetext{
${ }^{\text {*Corresponding author, e-mail: orlando.santana@upc.edu }}$ (C) BME-PT
} 
split-up of the ester linkage into alcohol and acid carboxylic groups. Doi et al. [5] as well as Yu et al. [6] argued that thermal and hydrolysis reactions for biocopolymers could be generated by random chain scission reactions of the ester groups following a mathematical model depending on its own composition.

Coupled with these two last mechanisms, intra(Figure 1c) and intermolecular (Figure 1d) transesterification reactions could also cause a drop in molecular weight at longer reaction times $[7,8]$. In fact, backbiting effect (zip-like depolymerization, see Figure 1b) leads to the formation of cyclic oligomers (lactide) and lactic acid which is catalyzed by the presence of monomers, oligomers or hydroxyl groups. Pyrolysis mechanisms should also be considered but at high temperatures $\left(>300^{\circ} \mathrm{C}\right)$ where cis-elimination (Figure 1e) gives rise to the formation of carboxylic acid groups and a polymer chain containing acryloyl groups [9].

The extrusion process can take advantage of these degradation reaction products when combined with reactive agents, promotes polymerization (chain extension), grafting, branching and functionalization [10]. On one side, reactive extrusion is an attrac- tive way to minimize the degradation effects during processing and to enlarge its processing window. On the other side, Corre et al. [11] as well as Pilla et al. [12] reported that chain architecture modification by chain branching enhances PLA melt properties. Chain branching degree depends on the functionality of the reactive agent and generally leads to an increase in molecular weight.

A new aspect that arises in this communication, in comparison with previous works $[11,12]$ on this subject, was the production of structural modified PD,L-LA sheets through a one-step reactive extrusion-calendering process (REX-Calendering) in a pilot plant. The main goal is to obtain sheets that could be used directly in the fabrication of thermoformed packaging and the evaluations of their final performances (melt rheology, thermal, mechanical and fracture behaviour).

The present communication shows the scaling up from an internal mixer study to a one step reactive extrusion-calendering process of two PD,L-LA extrusion grades, modified by a styrene-acrylic multifunctional oligomeric agent (SAmfE). The assessment of possible changes in the molecular weight and melt rheology is the aim of this publication. A

(a)

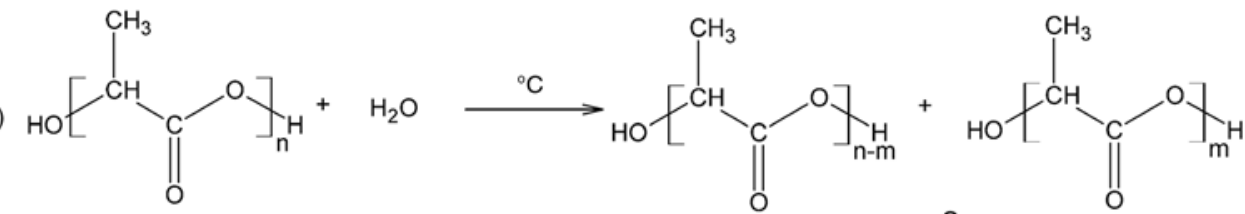

(b)

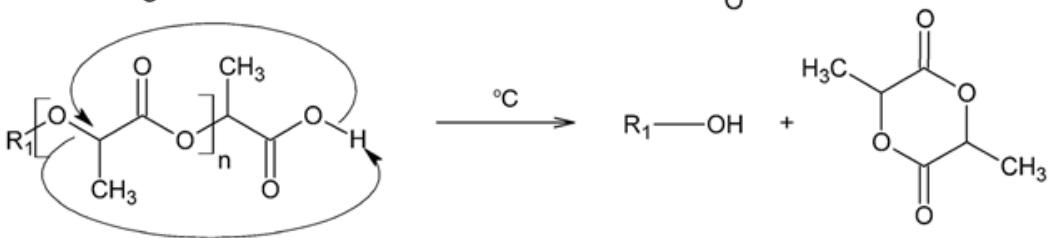

(c)

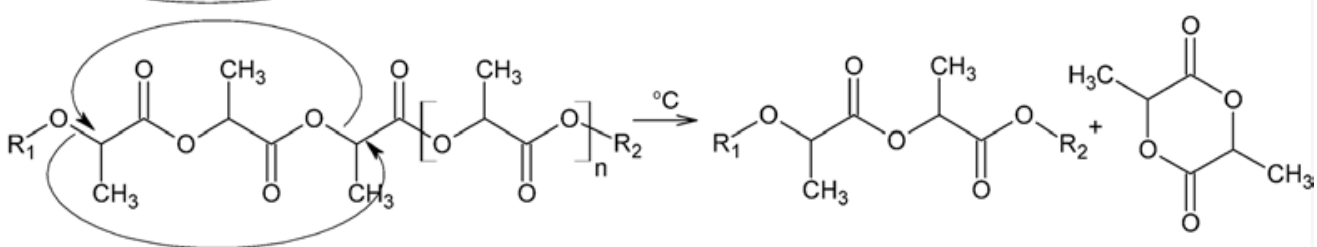

(d)

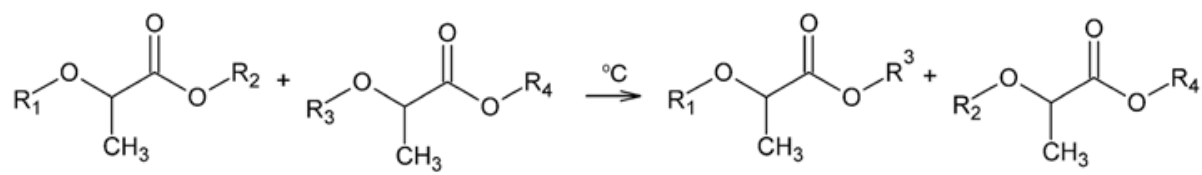

(e)

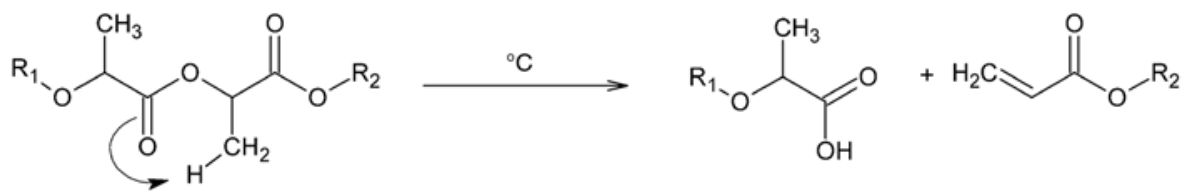

Figure 1. Reactions of degradation of PD,L-LA: (a) hydrolysis, (b) intramolecular transesterification (backbiting), (c) intramolecular transesterification, (d) intermolecular transesterification, (e) pyrolitic cis-elimination 
one-step REX-Calendering process using PD,L-LA and SAmfE has not yet been described in literature to the best of our knowledge.

\section{Experimental}

\subsection{Materials}

Two PD,L-LA extrusion grades supplied by NatureWorks ${ }^{\circledR}$ (Arendonk, Belgium) were used in this study whose characteristics are described in Table 1 $[13,14]$.

A styrene-acrylic multi-functional-epoxide oligomeric agent (SAmfE) was used as reactive agent, supplied by BASF $^{\circledR}$ (Ludwigshafen, Germany) (Joncryl-ADR-4300F) in flake form with a molecular weight of $5443 \mathrm{~g} \cdot \mathrm{mol}^{-1}$, an epoxy equivalent weight of $433 \mathrm{~g} \cdot \mathrm{mol}^{-1}$ and $T_{\mathrm{g}}=56^{\circ} \mathrm{C}$. The food compliance was delivered by the European Union for its use in food packaging. Figure 2 shows its generic structure [15].

\subsection{Processing}

\subsubsection{Lab-scale mixing: internal mixer}

Both grades of $\mathrm{PD}$,L-LA pellets were dried overnight at $55^{\circ} \mathrm{C}$ under vacuum prior to use in order to remove any excess moisture. SAmfE was stored overnight under vacuum. Melt blending of PD,L-LA and SAmfE was carried out in an internal mixer (Brabender Plastic-Corder W50EHT, Duisburg, Germany) with a mixing chamber volume of $55 \mathrm{~cm}^{3}$, at $180^{\circ} \mathrm{C}$ and with a screw rotation speed of $50 \mathrm{rpm}$. A continuous flow of $\mathrm{N}_{2}$ with a pressure of 3.5 bars was

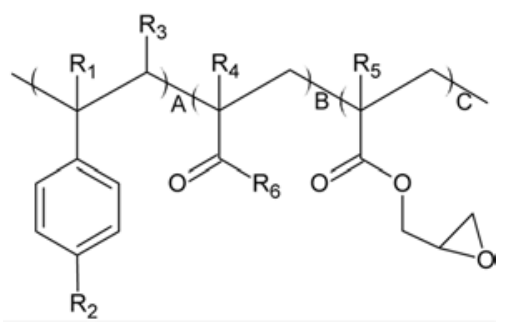

Figure 2. Structure of Joncryl-ADR-4300F used. $\mathrm{R}_{1}-\mathrm{R}_{5}$ are $\mathrm{H}, \mathrm{CH}_{3}$, a higher alkyl group, or combinations of them; $\mathrm{R}_{6}$ is an alkyl group, and $\mathrm{A}, \mathrm{B}$ are each between 1 and 20 and $\mathrm{C}$ between 1 and 12 . introduced into the mixing chamber in order to minimize degradation. SAmfE was added after the total fusion of PD,L-LA (3 min.).

In a first step, for each preparation, torque vs. mixing time was monitored for a prolonged time in order to follow the evolution of the reaction. An optimum reaction time of $13 \mathrm{~min}$ was deduced from these mixing experiments, as it will be explained in Section 3.1.1. Fresh blends were equally processed applying this optimum reaction time of $13 \mathrm{~min}$. After the reaction the material was extracted from the mixing chamber and cooled to room temperature. The obtained material was ground and vacuumdried overnight at $55^{\circ} \mathrm{C}$. Plates with a thickness of $1 \mathrm{~mm}$ were prepared by compression molding (40 bars) at $200^{\circ} \mathrm{C}$ for 10 minutes in a IQAP LAP PL-15 hot platen press.

\subsubsection{Pilot plan scale:} one step reactive extrusion-calendering

REX-Calendering process was performed in a corotating twin screw extruder $25 \mathrm{~mm}(L / D=36)$, (KNETER 25X24D, COLLIN, Ebersberg, Germany). Prior to extrusion, PD,L-LA pellets were dried at $80^{\circ} \mathrm{C}$ for 3 hours in a PIOVAN (DSN506HE, Venice, Italy) hopper-dryer (dew point $=-40^{\circ} \mathrm{C}$ ) and kept during all the extrusion process under the same conditions. The SAmfE was powdered using a mortar and pestle and then stored under vacuum. The screw speed was $40 \mathrm{rpm}$, the residence time was $4 \mathrm{~min}$ and the extruder was operated by starve feeding. The following temperature profile was used: $150^{\circ} \mathrm{C}$ (feeding zone), $170^{\circ} \mathrm{C}$ (melting zone) and $175^{\circ} \mathrm{C}$ (metering zone and die). Both polymer and SAmfE were simultaneously introduced in the hopper of the feeding zone under a nitrogen blanket ( 2.5 bars) after that the production line was started and stabilized with raw PD,L-LA material. The feeding rate of the SAmfE was adjusted to the polymer feeding rate in such way that a nominal dosage of $0.5 \%$ weight/weight of SAmfE was obtained.

Table 1. Technical specifications for both PD,L-LA grades used

\begin{tabular}{|c|c|c|c|c|c|c|c|}
\hline $\begin{array}{l}\text { PD,L-LA } \\
\text { grade }\end{array}$ & Sample I.D. & $\begin{array}{c}\text { D enantiomer } \\
\text { molar content } \\
{[\%]}\end{array}$ & $\begin{array}{c}\mathrm{M}_{\mathrm{n}} \\
{\left[\mathrm{kg} \cdot \mathrm{mol}^{-1}\right]}\end{array}$ & $\begin{array}{c}\mathbf{M}_{\mathrm{w}} \\
{\left[\mathbf{k g} \cdot \mathbf{m o l}^{-1}\right]}\end{array}$ & $\begin{array}{c}\text { MFI } \\
{[\mathrm{g} / 10 \mathrm{~min}]} \\
\left(210^{\circ} \mathrm{C} / 2.16 \mathrm{~kg}\right)\end{array}$ & $\begin{array}{c}\mathbf{T}_{\mathrm{mp}} / \mathbf{T}_{\mathbf{m e}}{ }^{*} \\
{\left[{ }^{\circ} \mathrm{C}\right]}\end{array}$ & $\begin{array}{l}\mathbf{X}_{\mathbf{c}}{ }^{*} \\
{[\%]}\end{array}$ \\
\hline Ingeo 4032D & PLA-2 & 2 & 90 & 181 & $6.4 \pm 0.3$ & $167 / 173$ & 40 \\
\hline Ingeo 2002D & PLA-4 & 4.25 & 99 & 187 & $5.8 \pm 0.2$ & $152 / 158$ & 35 \\
\hline
\end{tabular}

${ }^{*} T_{\mathrm{mp}}$ (maximum melting signal temperature), $T_{\mathrm{me}}$ (end melting signal temperature) and $X_{\mathrm{C}}$ (crystallinity degree) were determined for raw materials by DSC from the first heating cycle at $10^{\circ} \mathrm{C} \cdot \mathrm{min}^{-1}$, for which $\Delta H_{\mathrm{m}}^{0}=93.6 \mathrm{~J} \cdot \mathrm{g}^{-1}$. 
Table 2. Nomenclature used for all processed samples in the study

\begin{tabular}{|c|c|c|c|}
\hline Grade & Mixing process & Sample I.D. & $\begin{array}{c}\text { Amount of } \\
\text { SAmfE added } \\
{[\% w / w]}\end{array}$ \\
\hline \multirow{5}{*}{ Ingeo 4032D } & \multirow{3}{*}{ Internal mixer } & PLA-2 "neat" & 0 \\
\hline & & PLA-2+0.5J & 0.5 \\
\hline & & PLA-2+1J & 1 \\
\hline & \multirow{2}{*}{ REX-Calendering } & PLA-2 extr. & 0 \\
\hline & & PLA-2-REX & 0.5 \\
\hline \multirow{5}{*}{ Ingeo 2002D } & \multirow{3}{*}{ Internal Mixer } & PLA-4 "neat" & 0 \\
\hline & & PLA-4+0.5J & 0.5 \\
\hline & & PLA-4+1J & 1 \\
\hline & \multirow{2}{*}{ REX-Calendering } & PLA-4 extr. & 0 \\
\hline & & \begin{tabular}{|l|} 
PLA-4-REX \\
\end{tabular} & 0.5 \\
\hline
\end{tabular}

Furthermore, vacuum was applied in the metering zone to remove any volatiles formed during the reaction. Sheets with $100 \mathrm{~mm}$ nominal width and a nominal thickness of $1 \mathrm{~mm}$ were calendered (Techline CR72T, COLLIN, Ebersberg, Germany). The chill roll temperature was set to $50^{\circ} \mathrm{C}$. Using the above described processing parameters, about $40 \mathrm{~m}$ of calendered sheet were obtained.

Samples prior to SAmfE addition (referred to as PLA-2 extr. and PLA-4 extr.) and also from the stabilized regime as it will be explain in Section 3.1.2. (regime 2 at about $30 \mathrm{~min}$ ) were analyzed (referred to as PLA-2-REX and PLA-4-REX).

All prepared samples are specified in Table 2; samples were distinguished by their different $D$ enantiomer molar content, the amount of added SAmfE and the type of mixing process.

\subsection{Characterization techniques}

\subsubsection{Size exclusion chromatography (SEC)}

Average molecular weights $\left(M_{\mathrm{n}}\right.$ and $\left.M_{\mathrm{w}}\right)$ and the polydispersity index (PDI) were determined using a Hitachi mono-detector chromatograph with a separation column of PLHFIP gel (Polymer Laboratories, Santa Clara, CA, USA) running at room temperature. Mobile phase was hexafluoroisopropanol (HFIP) containing $6,8 \mathrm{~g} \cdot \mathrm{L}^{-1}$ of sodium trifluoroacetate to prevent polyelectrolyte effect. $100 \mu \mathrm{L}$ were injected and the concentration of each sample was $0,2 \mathrm{w} / \mathrm{v} \%$. Calibration was performed with PMMA samples (Easycal kit, Polymer Laboratories, Santa Clara, CA, USA).

\subsubsection{Rheological dynamic analysis (RDA)}

An oscillatory rheometer (AR-G2, TA Instrument, New Castle, DE, USA) equipped with parallel-plate geometry of $25 \mathrm{~mm}$ diameter with a gap of $1 \mathrm{~mm}$ was used. Tests were conducted under controlled deformation conditions at $0,2 \%$ (LVR) at 172,180 and $200^{\circ} \mathrm{C}$. Prior to use, samples were dried at $55^{\circ} \mathrm{C}$ for $12 \mathrm{~h}$ under vacuum and kept during tests under nitrogen flow to minimize oxidation and to maintain a dry environment. Dynamic frequency sweeps were carried out over an angular frequency $(\omega)$ range of $628.3-0.06283 \mathrm{rad} \cdot \mathrm{s}^{-1}$.

In order to ensure sufficient data on the terminal region, creep experiments were performed at $180^{\circ} \mathrm{C}$ under a constant stress of $19.56 \mathrm{~Pa}$. The creep data were converted into the relaxation spectrum $H(\lambda)$ using the NLREG method. Subsequently, the storage and loss modulus $G^{\prime}(\omega)$ and $G^{\prime \prime}(\omega)$ were calculated by two Fredhom integral equations [16, 17]. Master curves were referenced at $180^{\circ} \mathrm{C}$ and were constructed from the combination of time-temperature superposition (TTS) and creep tests. The TTS principle was verified, plotting the phase angle delta versus the absolute value of the complex modulus [18].

The rheological parameters were analyzed using the 'modified Carreau-Yasuda equation' (c.f. Equation (1)) in order to take into account the several distinctly separated relaxation processes in the viscosity functions due to the possible presence of long chain branching (LCB) [19]:

$$
\left|\eta^{*}(\omega)\right|=\eta_{0} \prod_{\mathrm{i}=1}^{\mathrm{m}}\left[1+\left(\tau_{\mathrm{i}} \omega\right)^{\alpha_{i}}\right]^{\frac{\nu_{\mathrm{i}}-1}{\alpha_{\mathrm{i}}}}
$$

where $\eta_{0}$ represents the zero-shear viscosity $[\mathrm{Pa} \cdot \mathrm{s}]$ and $m$ the number of curvatures in the viscosity function. $\tau_{\mathrm{i}}$ and $\alpha_{\mathrm{i}}$ represent characteristic relaxation times [s] and the width of each transition region between each different curvature. Finally, $v_{\mathrm{i}}$ is the respective power law index of the latter ones. Equation (1) results in the conventional Carreau-Yasuda model for $m=1$.

\section{Results and discussion}

Reactive extrusion of polyesters and epoxies as reactive agent has been extensively studied and the reactions are well established. Both polyester end groups (i.e. carboxyl and hydroxyl groups) can react with epoxy functional groups via ring-opening reactions, creating covalent bonds with hydroxyl groups [20]. However, a higher reactivity of epoxy towards the carboxyl groups compared to hydroxyl groups was reported in the literature [21]. This is due to the 
strong polarization of the hydroxyl groups of carboxylic acid [22].

Since a polyfunctional SAmfE was used in this work (functionality $f_{\mathrm{n}} \leq 12$ ) and based on previous works dealing with reactions between polyesters and epoxies, a variety of different polymer topologies may be obtained, as shown in Figure 3. In a first step, PD,L-LA carboxyl groups open SAmfE

\section{Step 1:}<smiles>[R3]C([13CH3])(CC)C(=O)OCC(O)COC(=O)O</smiles>

(a) Grafting

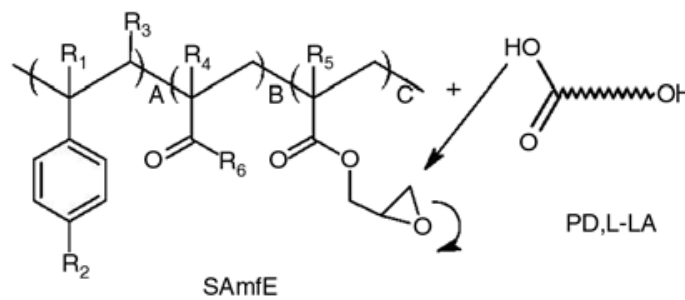<smiles>[B]C(CC)(CC([B])(CC(=O)O)C(=O)OCC(O)COC(=O)O)C(=O)O</smiles>

(b) Chain Extension

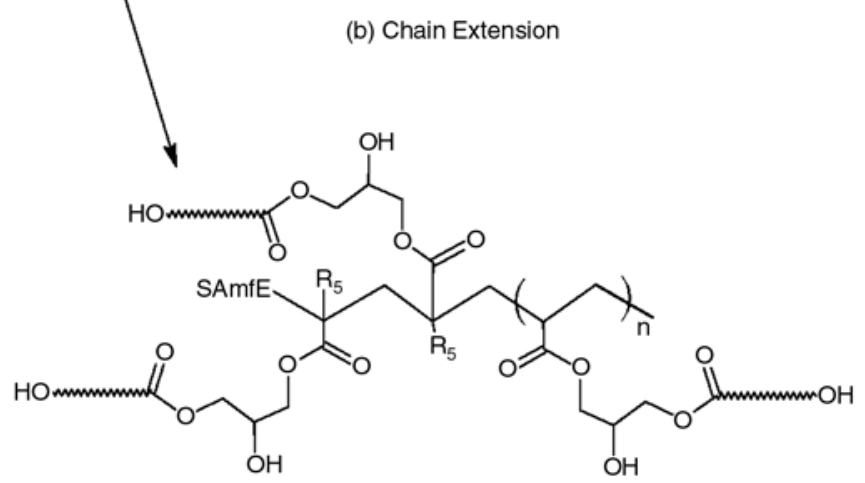

Step 2:

(c) n arms star<smiles>OC(O)(O)C1CO1</smiles>

(c) n arms star

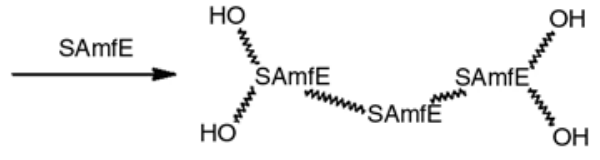

(d) Streched $\mathrm{H}$

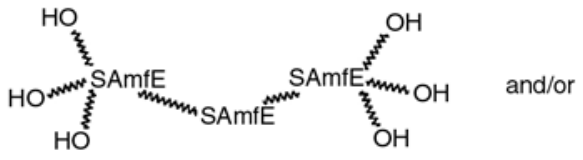

(e) Pom-Pom<smiles>O[14C](O)[14C@H](O)[14C@@H](O)[14C@@H](O)[14CH](O)O</smiles>

(f) Comb<smiles>O[14C](O)[14C@@H]([14CH](O)O)[14C@@H](O)[14C](O)(O)O</smiles>

(g) Tree

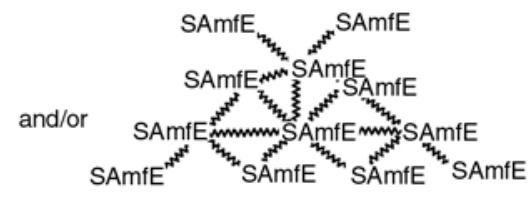

(h) Network structure

Figure 3. Sketch of the three possible reactions ( $a, b, c)$ occurring between PD,L-LA and SAmfE agent, followed by the possible topology structures, $(\mathrm{d}, \mathrm{e}, \mathrm{f}, \mathrm{g}, \mathrm{h})$ created for longer reaction times 
epoxy rings which results in (Figure 3a) grafting reactions followed by (Figure $3 \mathrm{~b}$ ) chain extension reactions and finally (Figure $3 \mathrm{c}$ ) $n$ arms star formation. In a second step, for longer reaction times, the SAmfE product may further react due to its high reactivity and therefore lead to (Figure $3 \mathrm{~d}$ ) stretched $H$, (Figure 3e) pom-pom, (Figure 3f) comb or (Figure $3 \mathrm{~g}$ ) tree type structures. Finally, an excess of SAmfE may generate a (Figure $3 \mathrm{~h}$ ) network structure.

\subsection{Reactive modification process monitoring}

\subsubsection{Lab-scale mixing: internal mixer}

As a first step, the effect of SAmfE addition on both PD,L-LA grades viscosity was evaluated in an internal mixing process as shown in Figure 4. The torque versus time was monitored over a prolonged time ( 35 minutes) in order to follow the evolution of the reaction.

Although not shown in Figure 4, the bulk temperature increased from 180 to $200^{\circ} \mathrm{C}$ during mixing process for all samples except PLA-2+1J. This is due to the mechanical shearing and the effect of the exothermal nature of the reaction.

According to Figure 4, the torque of PLA-2 and PLA-4 "neat" samples decreased monotonously over time. This decrease was more pronounced for PLA2 "neat" samples than PLA-4 ones. This may be explained by the combination of two or more degra-

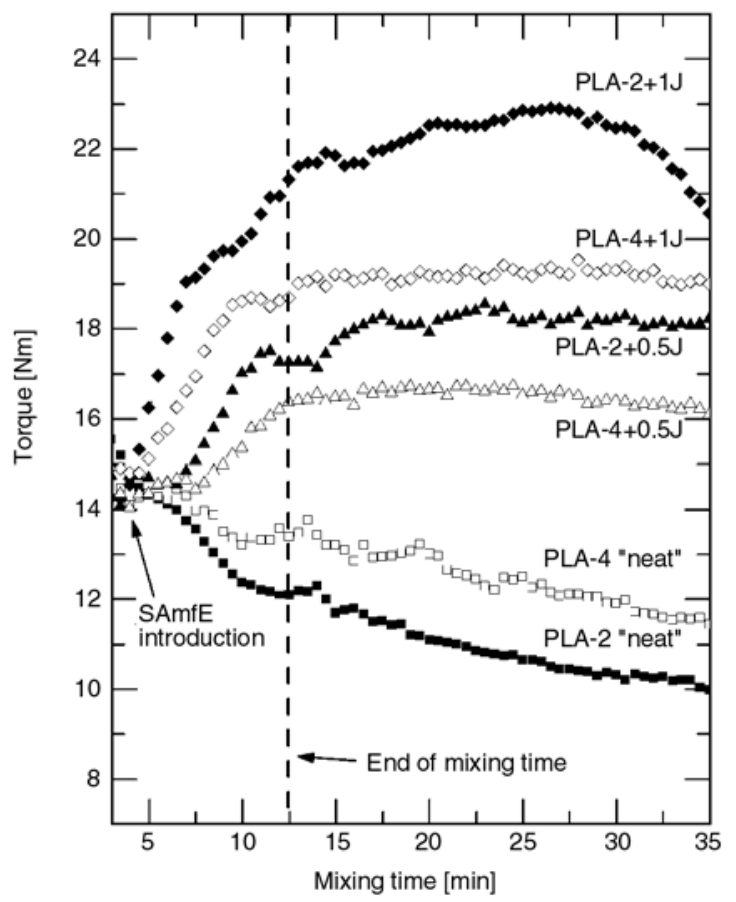

Figure 4. Torque versus mixing time for the samples processed by internal mixing process dation mechanisms, namely backbiting and thermal degradation occurring during mixing process. On one hand PLA-2 presents a higher content of terminal functional groups (lower $M_{\mathrm{n}}$ ) than PLA-4 (c.f. Table 1), which may act as a catalyst of backbiting degradation during processing. And on the other hand, as already observed by Bigg [23] for semicrystalline polyesters, the thermal degradation depends on the width of the processing windows. PLA-4 presents a broader processing window (200$\left.T_{\mathrm{me}}=42^{\circ} \mathrm{C}\right)$ than PLA-2 $\left(=27^{\circ} \mathrm{C}\right)$ according to their respective end melting signal temperature (c.f. Table 1) which will decrease the local shear field applied to the material during mixing and therefore the thermal degradation. A higher proportion of terminal functional groups (hydroxyl as well as carboxyl groups) was therefore produced for PLA-2 than PLA-4 during processing.

In contrast, when both PD,L-LA grades were mixed with SAmfE agent, a strong torque increase was observed. This increase was in all cases higher for PLA-2 than PLA-4 samples. This may be due to the higher amount of PD,L-LA terminal functional groups in PLA-2 samples which results in a higher reactivity towards SAmfE agent. As can be seen in Figure 4, some torque fluctuations can be observed between 10 and 15 minutes for PLA-2+0.5J and PLA-4+1J samples. This might be a consequence of the stick and split behaviour on the wall of the internal mixer due to a possible increase of the melt elasticity.

The torque of PLA-2+1J sample did not reach stabilization over time but increased continuously, reaching a maximum around 28 minutes and then decreasing. Due to the high content of SAmfE and the apparent higher reactivity of PLA-2 a remarkable increase in viscosity was observed. Crosslinking reactions might have taken place together with branching reactions, giving rise to network structure formation (c.f. Figure $3 \mathrm{~h}$ ). At some point (28 $\mathrm{min}$ ) the combination of high bulk temperature $\left(\approx 215^{\circ} \mathrm{C}\right)$ and a high shear could initiate some degradation processes, resulting in a torque decrease as the network structure may be broken.

An optimum reaction time under these conditions was considered as the point when the torque stabilized, avoiding an excessive reaction time to prevent the aforementioned secondary reactions. Considering these results, an optimum mixing time of 13 min was chosen which corresponds to the first 
torque stabilization (plateau on torque trace (c.f. Figure 4)). Fresh blends using this chosen processing time of $13 \mathrm{~min}$ were produced. After melt blending, the materials were compression molded into thin sheets, the latter were used for further RDA and SEC characterization.

\subsubsection{Pilot plant scale:}

one step reactive extrusion-calendering

Based on the internal mixer study and to minimize the risk of gelation due to the possible crosslinking reactions and low final product quality, the comparison between both PD,L-LA grades during the REX-calendering process was only carried out with a nominal SAmfE content of $0.5 \mathrm{w} / \mathrm{w} \%$.

As a first step, frequency sweep tests at $190^{\circ} \mathrm{C}$ (exit temperature of the film) were carried out in order to determine the sheet length that showed the same modification degree. For these tests, the complex viscosity at $0.08 \mathrm{rad} / \mathrm{s}$ was used as the monitoring parameter and was determined in 15 points along the sheet length. Therefore, a profile of modification along the extruded sheet, expressed as extrusion time was plotted and represented in Figure 5.

As can be seen in Figure 5, three different regimes were observed. The first regime corresponds to the time needed to reach the reactive entities saturation in the dosing zone of the extruder. In both cases this

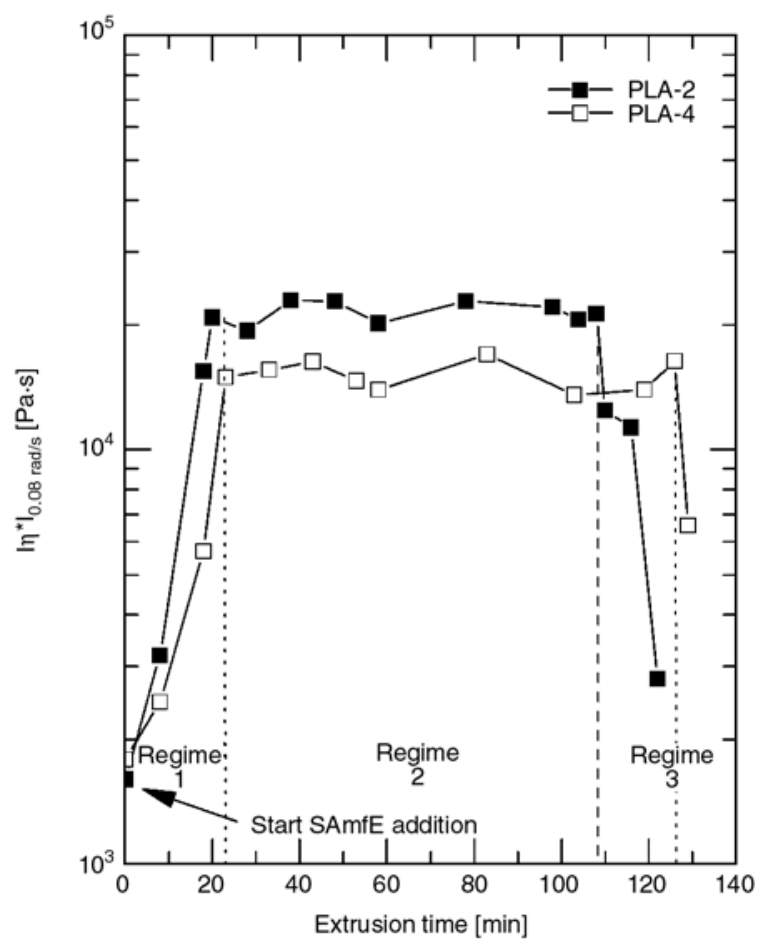

Figure 5. Complex viscosity (at $0,08 \mathrm{rad} / \mathrm{s}$ ) versus extrusion time at $190^{\circ} \mathrm{C}$ for REX-Calendering samples time was longer than in the previous internal mixer preparation (20 min versus $13 \mathrm{~min}$ ). This situation could be expected if the dynamic nature (continuous flow) of the extrusion process is considered. It is well established in the industry that, the stabilization of a production line requires a specific time in order to reach a stable regime. For the processing conditions employed in this work, this was the case for REX-Calendered samples. In fact, a specific time was needed to reach the saturation of the reactive species involved such as carboxyl groups and epoxies. In the case of the internal mixer, it must be remembered that the mixing process works by batch in with no continuous 'discharge' of the bulk mixed is done contrary to the extrusion process.

In the second regime, this saturation condition have been reached and all specimens possess a similar viscosity, indicating that a similar degree of modification (chain extension and/or branching) is obtained. The third regime shows a viscosity decrease because SAmfE dosage was stopped.

It should be noted that the stabilization was reached after $\sim 20$ min for both PD,L-LA grades. Furthermore, a higher viscosity was reached in the case of PLA-2 compared to PLA-4 as was also observed in the internal mixer study.

\subsection{Molecular weight distribution (MWD) analysis}

SEC tests were performed on all of the samples in order to determine the difference in the molecular weight distribution due to the reaction of both PD,L-LA grades with SAmfE agent. Figure 6 shows the molecular weight distribution curves obtained for PLA-2 samples for both processing methods: (a) internal mixer samples and (b) REX-Calendered samples in which each curve was normalized by the maximum $\mathrm{d} W / \mathrm{d} \log M$ of the "neat" and extr. grade, respectively. Similar curves were obtained for PLA-4 samples.

According to SEC tests, unmodified PLA-2 "neat" (c.f. Figure 6a) samples displayed a monomodal distribution which changed to a bi- and three-modal one with increasing SAmfE content. This was associated to the presence of two or three different hydrodynamic volumes, respectively, which could be a consequence of significantly different chain topologies. Substantially, a similar tendency could be seen for PLA-4 samples processed in the internal mixer, also exhibiting bi- and trimodal MWD. 

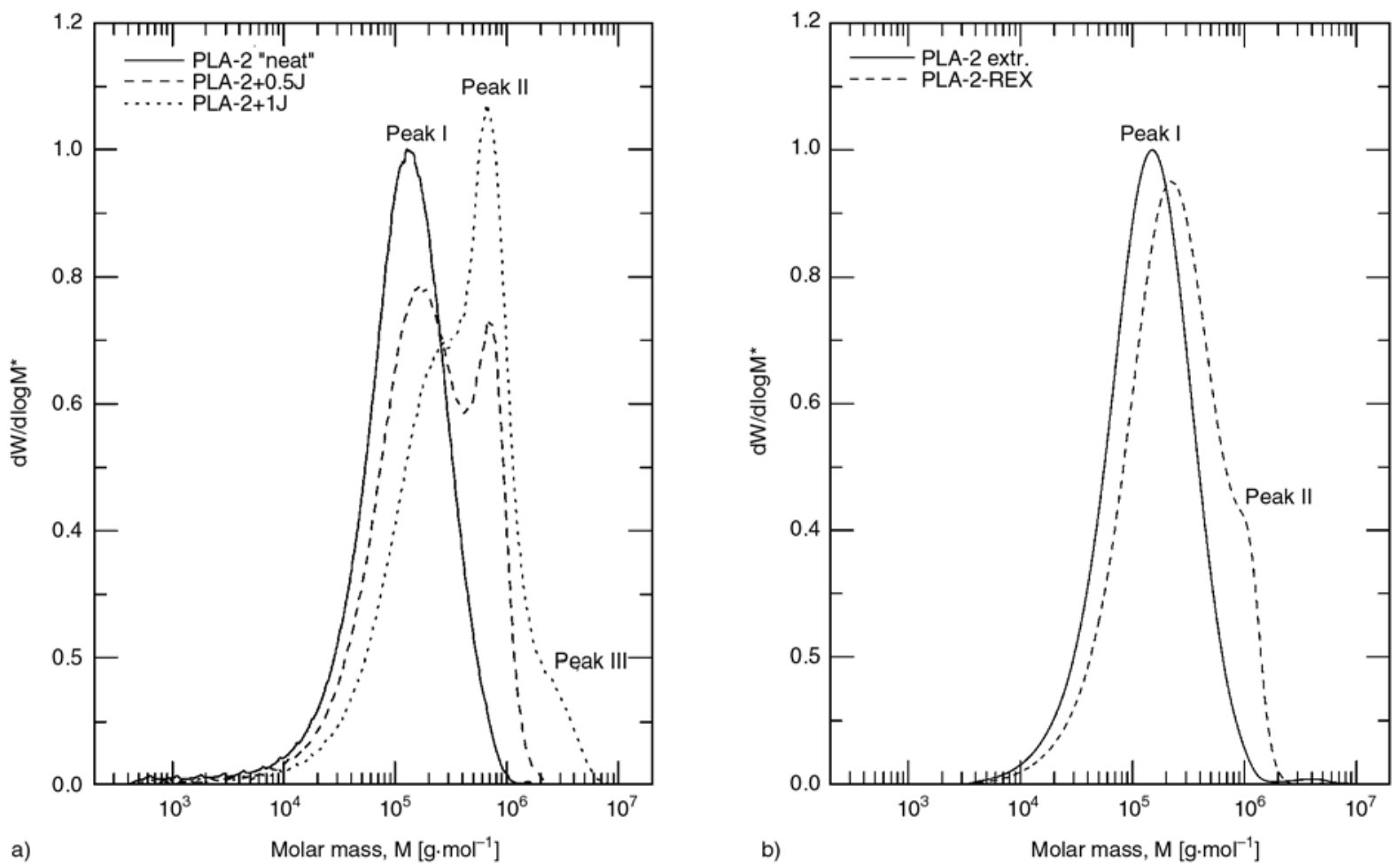

Figure 6. Molecular weight distribution for (a) internal mixer and (b) REX-Calendering PLA-2 samples. * Normalized by the maximum of the "neat" and extr. grade, respectively.

As can be seen in Figure 6b, a similar behaviour in the molecular weight distribution is noticeable for REX-Calendered samples. When SAmfE is added, a less evident bimodal distribution in these latter samples compared to internal mixer samples may be observed. Possibly, a less branched topology of the chains was generated due to a shorter reaction time. Therefore the differences in hydrodynamic volume were less pronounced in REX-Calendered samples and these less branched populations probably eluted together with the linear populations.

Due to the linear topology of unmodified PLA samples, the first peak at low molecular weight for all modified samples was attributed to a linear population and the second peak (at higher molecular weight) to a branched chain population of the polymer. Special attention should be paid to the samples PLA-2+1 $\mathrm{J}$ and PLA-4+1J processed in internal mixer. These samples reveal a third peak (Peak III) at very high molecular weight which may be attributed to the presence of highly branched populations or even to network structures.

It is well known that classical SEC technique (monodetector) is not a suitable method to accurately determine the molecular weight of branched samples due to the fact that hydrodynamic volumes are greatly affected by the molecular topology. Prepara- tive SEC experiments [24] and/or multi-detector technique may be a more appropriate technique to study modified samples but this analysis would be beyond the scope of this work. However, qualitative information about the complex molecular weight distribution can be extracted from classical SEC data in order to reveal a branching effect. Therefore, a deconvolution was applied to each size exclusion chromatogram in order to do a detailed analysis and results are presented in Table 3.

According to Table 3, a drop in $M_{\mathrm{w}}$ for unmodified PLA-2 and PLA-4 ("neat" and extr. ones) samples compared to raw, unprocessed materials was detected (c.f. Table 1). This is due to the action of different degradation mechanisms during processing. This decrease seems to be higher for PLA-2 sample processed in the internal mixer (PLA-2 "neat"). It appears that the mixing conditions in the internal mixer generated more degradation than in continuous extrusion process.

For both mixing process, when $0,5 \mathrm{w} / \mathrm{w} \% \mathrm{SAmfE}$ was added, $M_{\mathrm{w}}$ as well as the PDI of peak I increased, remaining the dominant fraction in all cases (higher relative area of the deconvolution). It could be a consequence of possible chain extensions coupled with co-elution problems of different chain topology structures. 
Table 3. Numerical analysis of the molecular weight distribution for samples prepared by internal mixing and REX-Calendering process

\begin{tabular}{|c|c|c|c|c|c|c|}
\hline Mixing process & Sam & & $\begin{array}{c}\mathbf{M}_{\mathbf{n}} \\
{\left[\mathrm{g} \cdot \mathbf{m o l}^{-1}\right]}\end{array}$ & $\begin{array}{c}\mathbf{M}_{\mathrm{w}} \\
{\left[\mathrm{g} \cdot \mathrm{mol}^{-1}\right]}\end{array}$ & PDI & $\begin{array}{c}\text { Area } \\
{[\%]}\end{array}$ \\
\hline \multirow{8}{*}{ Internal Mixer } & PLA-2 "neat" & global & 71184 & 154729 & 2.2 & - \\
\hline & \multirow{3}{*}{ PLA- $2+0.5 \mathrm{~J}$} & global & 101675 & 282476 & 2.8 & - \\
\hline & & Peak I* & 88222 & 196768 & 2.2 & 57.3 \\
\hline & & Peak II ${ }^{*}$ & 706160 & 763589 & 1.1 & 42.7 \\
\hline & \multirow{4}{*}{ PLA-2+1J } & global & 116349 & 513191 & 4.4 & - \\
\hline & & Peak I* & 86147 & 283157 & 3.3 & 41.1 \\
\hline & & Peak II ${ }^{*}$ & 663154 & 743794 & 1.1 & 33.7 \\
\hline & & Peak III* & 1735205 & 2351076 & 1.4 & 25.2 \\
\hline \multirow{4}{*}{ REX-Calendering } & PLA-2 extr. & global & 84207 & 179441 & 2.1 & - \\
\hline & \multirow{3}{*}{ PLA-2-REX } & global & 119533 & 297307 & 2.5 & - \\
\hline & & Peak I* & 112851 & 246077 & 2.2 & 71 \\
\hline & & Peak II $^{*}$ & 990320 & 1058111 & 1.1 & 29 \\
\hline \multirow{8}{*}{ Internal Mixer } & PLA-4 "neat" & global & 82283 & 182560 & 2.2 & - \\
\hline & \multirow{3}{*}{ PLA-4+0.5J } & global & 104356 & 348515 & 3.3 & - \\
\hline & & Peak I* & 95021 & 253967 & 2.7 & 60.4 \\
\hline & & Peak II ${ }^{*}$ & 1123368 & 1221521 & 1.1 & 39.6 \\
\hline & \multirow{4}{*}{ PLA-4+1J } & global & 100650 & 331452 & 3.3 & - \\
\hline & & Peak I* & 87428 & 242884 & 2.8 & 57.5 \\
\hline & & Peak II $^{*}$ & 708973 & 782740 & 1.1 & 35.6 \\
\hline & & Peak III* & 1806505 & 1923430 & 1.1 & 6.9 \\
\hline \multirow{4}{*}{ REX-Calendering } & PLA-4 extr. & global & 98087 & 181815 & 1.8 & - \\
\hline & \multirow{3}{*}{ PLA-4-REX } & global & 118650 & 246789 & 2.1 & - \\
\hline & & Peak I* & 111992 & 205125 & 1.8 & 78.4 \\
\hline & & Peak II & 794821 & 842948 & 1.1 & 21.6 \\
\hline
\end{tabular}

${ }^{*}$ Results obtained from the deconvolution analysis.

Slight differences between both mixing processes may be observed when comparing the relative areas of peaks I and II. As can be seen in Table 3, for internal mixer samples, the relative area proportion attributed to chain branched topology (Peak II) is always higher compared to the REX-Calendered samples. This may be expected if the higher degree of degradation in internal mixer processing is considered. In fact, the formation of a higher concentration of carboxyl groups promoted an increase in coupling or branching reactions in the presence of the SAmfE agent and therefore a higher branching degree.

Regarding the internal mixer preparation, when the SAmfE content was doubled (from $0.5 \mathrm{w} / \mathrm{w} \%$ to $1 \mathrm{w} / \mathrm{w} \%)$, the respective areas of peak II and III increased at the expense of peak I, indicating an increase of this 'new' chain topology content which was attributed to long chain branching and/or more complex topology structures (comb, tree or network structure). For PLA-2+1J sample, the summation of peak II and III relative areas exceeds the peak I area. Possibly a network structure coupled with long chain branching was generated due to the pronounced modification degree reached in this sys- tem. Evidence of this last assumption was obtained by visual inspection and solubility tests which showed the existence of gel structures.

\subsection{Rheological characterization}

Rheological master curves referenced at $180^{\circ} \mathrm{C}$ for internal mixer as well as REX-Calendered samples are shown in Figure 7. Each sample exhibits a Newtonian plateau at low angular frequencies (except PLA-2+1J sample) and is shear thinned at high frequencies in its respective viscosity functions $\left|\eta^{*}(\omega)\right|$ as can be seen in Figure 7.

Special attention was paid for the analysis of PLA$2+1 \mathrm{~J}$ samples prepared by internal mixing process (c.f. Figure 7a). A clear shoulder in the viscosity functions $\left|\eta^{*}(\omega)\right|$ is observed at low angular frequencies. This is a common behaviour for heterogeneous systems. In fact, at least one of the different phases has different relaxation times such as emulsions, immiscible polymer blends or polymer/inorganic filler composites. In all these cases, the Palierne's model [25] has been found to successfully predict the linear viscoelastic behavior. In this model, the viscoelasticity of both phases as well as 

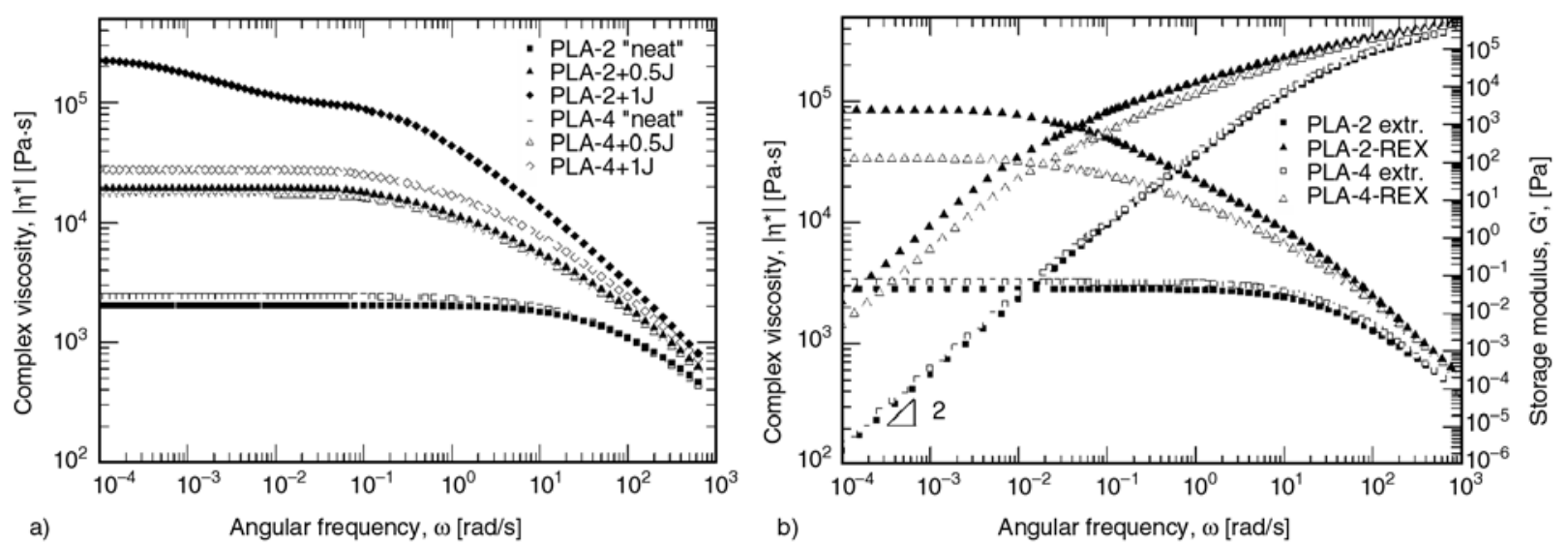

Figure 7. Rheological master curves at $180^{\circ} \mathrm{C}$ for samples prepared by (a) internal mixer and (b) REX-Calendering process

the hydrodynamic interactions, the droplet size, the size distribution and finally the interfacial tension between both phases are considered. However, this kind of analysis is beyond the scope of the present work.

The rheological behaviour of branched/partially crosslinked structures, such as the sample PLA$2+1 \mathrm{~J}$, may be predicted using their corresponding SEC data. In fact, the majority presence of populations with significant different molecular topology (such as populations corresponding to Peak II and Peak III in Figure 6a) has quite distinct relaxation time compared to the linear population and commonly a shoulder is observed in its viscosity function at low angular frequencies.

As can be seen in Figure $7 \mathrm{a}$ and $7 \mathrm{~b}$ for modified samples, the shear-thinning region of the viscosity function seems to present several curvatures. This latter observation leads to an insufficient accuracy to obtain a correct fitting of the viscosity function with the Carreau-Yasuda model. Stadler and Münstedt [19] reported a similar behaviour in their stud-

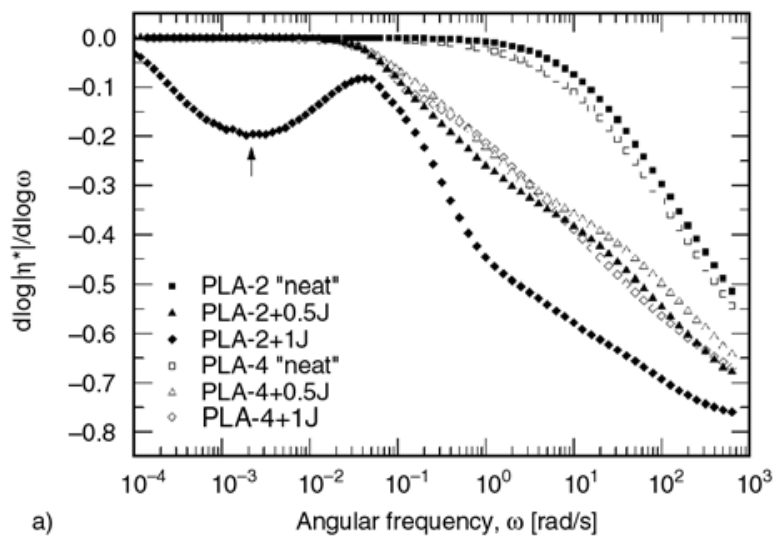

ies, based on metallocene-catalyzed PE. The presence of long-chain branching brings a complexity in the relaxation processes, leading to the existence of additional curvatures in $\left|\eta^{*}(\omega)\right|$. As a result, the viscosity function may be categorized into three different types considering the shape of the double logarithmic derivative $\mathrm{d} \log \left|\eta^{*}\right| / \mathrm{d} \log \omega$ versus $\log \omega$ curve. A 'modified Carreau-Yasuda model' (c.f. Equation (1)) was therefore used in order to consider the several distinctly separated relaxation processes in the viscosity function to obtain a proper fitting of this latter one [19].

The double logarithmic derivative of the viscosity functions versus $\log \omega$ is showed in Figure 8a for internal mixer samples and $8 \mathrm{~b}$ for REX-Calendered samples.

As can be seen in Figure 8 for all unmodified PLA samples, the double logarithmic slope $\mathrm{d} \log \left|\eta^{*}\right| / \mathrm{d} \log \omega$ versus $\log \omega$ decreases monotonously which is the common behaviour for linear polymers. In contrast, all modified samples, excepting PLA-2+1J, show a shoulder in the double logarithmic derivative which

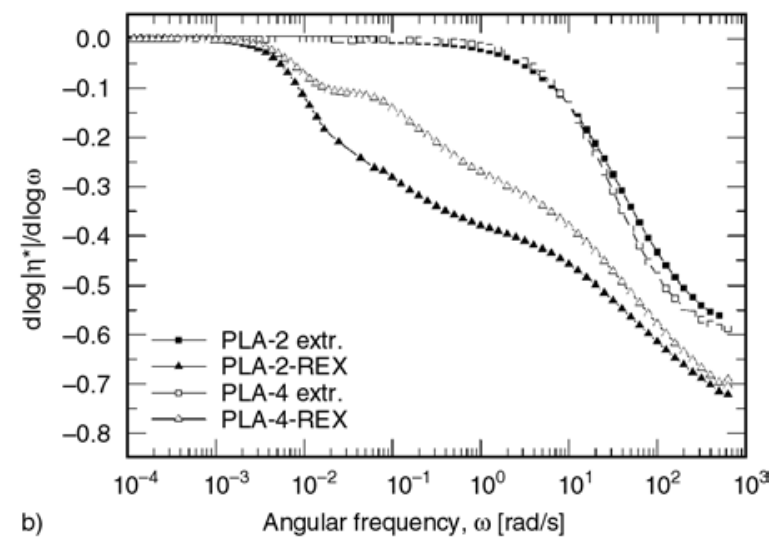

Figure 8. Double logarithmic derivative of the viscosity function versus angular frequency $(\omega)$ for samples prepared by (a) internal mixing and (b) REX-Calendering process 
Table 4. Rheological parameters at $180^{\circ} \mathrm{C}$ for the samples prepared by internal mixing process

\begin{tabular}{|l|c|c|c|c|c|c|}
\hline \multicolumn{1}{|c|}{ Parameters } & PLA-2 “neat" & PLA-2+0.5J & PLA-2+1J & PLA-4 “neat" & PLA-4+0.5J & PLA-4+1J \\
\hline$\eta_{0}[\mathrm{kPa} \cdot \mathrm{s}]$ & $2.05 \pm 0.01$ & $19.4 \pm 0.2$ & $233 \pm 5$ & $2.44 \pm 0.01$ & $17.1 \pm 0.2$ & $27.7 \pm 0.2$ \\
\hline$\tau_{1}[\mathrm{~s}]$ & $0.019 \pm 0.001$ & $6.4 \pm 0.6$ & $25 \pm 10$ & $0.016 \pm 0.001$ & $6.4 \pm 0.6$ & $14.56 \pm 0.5$ \\
\hline$\alpha_{1}$ & $0.91 \pm 0.01$ & $1.5 \pm 0.1$ & $3 \pm 2$ & $0.72 \pm 0.01$ & $1.5 \pm 0.1$ & $2.68 \pm 0.3$ \\
\hline$v_{1}$ & $0.43 \pm 0.01$ & $0.75 \pm 0.02$ & $0.8 \pm 0.1$ & $0.42 \pm 0.01$ & $0.76 \pm 0.02$ & $0.865 \pm 0.007$ \\
\hline$\tau_{2}[\mathrm{~s}]$ & - & $0.04 \pm 0.03$ & - & - & $0.05 \pm 0.03$ & $0.17 \pm 0.02$ \\
\hline$\alpha_{2}$ & - & $0.8 \pm 0.1$ & - & - & $0.84 \pm 0.09$ & $0.81 \pm 0.03$ \\
\hline$v_{2}$ & - & $0.59 \pm 0.03$ & - & - & $0.61 \pm 0.03$ & $0.49 \pm 0.01$ \\
\hline$R^{2}$ & 0.9989 & 0.9981 & 0.3502 & 0.9983 & 0.9983 & 0.9985 \\
\hline
\end{tabular}

Table 5. Rheological parameters at $180^{\circ} \mathrm{C}$ for the samples prepared by REX-Calendering process

\begin{tabular}{|l|c|c|c|c|}
\hline \multicolumn{1}{|c|}{ Parameters } & PLA-2 extr. & PLA-2-REX & PLA-4 extr. & PLA-4-REX \\
\hline$\eta_{0}[\mathrm{kPa} \cdot \mathrm{s}]$ & $2.837 \pm 0.005$ & $86.0 \pm 0.6$ & $3.232 \pm 0.009$ & $34.1 \pm 0.3$ \\
\hline$\tau_{1}[\mathrm{~s}]$ & $0.025 \pm 0.001$ & $45.3 \pm 0.2$ & $0.027 \pm 0.001$ & $50.09 \pm 0.2$ \\
\hline$\alpha_{1}$ & $0.92 \pm 0.01$ & $1.4 \pm 0.3$ & $0.92 \pm 0.02$ & $1.2 \pm 0.01$ \\
\hline$v_{1}$ & $0.39 \pm 0.01$ & $0.644 \pm 0.002$ & $0.38 \pm 0.01$ & $0.841 \pm 0.006$ \\
\hline$\tau_{2}[\mathrm{~s}]$ & - & $0.035 \pm 0.003$ & - & $0.158 \pm 0.003$ \\
\hline$\alpha_{2}$ & - & $0.79 \pm 0.07$ & - & $0.71 \pm 0.05$ \\
\hline$v_{2}$ & - & $0.66 \pm 0.02$ & - & $0.62 \pm 0.01$ \\
\hline$R^{2}$ & 0.9984 & 0.9976 & 0.9986 & 0.9983 \\
\hline
\end{tabular}

is reflected in the viscosity functions by two different curvatures in the pseudoplastic zone. PLA-2+1J sample presents a minimum in the double logarithmic slope (indicated by an arrow) which may be the effect of its very high molecular mass $M_{\mathrm{w}}$ (c.f. Table 3 ) or a very high degree of branching explained by the high content of reactive agent introduced during reactions (c.f. Figure 4). As previously discussed by Stadler and Münstedt [19], the modified Carreau-Yasuda model proposed is not able to fit this minimum and the validity of this model for highly branched polymers is questioned. Even though, and just for comparative study the modified Carreau-Yasuda model was fitted. Tables 4 shows the rheological parameters for PLA-2+1J samples. Some differences between both mixing processes may be observed when comparing the shape of the double logarithmic derivative versus $\log \omega$. As can be seen in Figure 8a and 8b, the decrease in the double logarithmic derivative for modified REX-Calendered samples are initiated at substantially lower angular frequencies compared to modified internal mixer samples. Thus, the molecular modifications induced by REX-Calendering process seem to have a greater impact on the molecular dynamics during flow, increasing relaxation processes.

Rheological parameters for internal mixing process and REX-Calendering process are presented in Tables 4 and 5 , respectively.
According to Tables 4 and 5, the results suggest that the zero-shear viscosity as well as characteristic times $\left(\tau_{\mathrm{i}}\right)$ increase with increasing SAmfE content. The transition region $\left(\alpha_{1}\right)$ between the Newtonian region and the first curvature is broadened together with the apparition of a second curvature. This behaviour reflects the presence of additional relaxation modes due to a possible presence of long chain branching topology generated during reactions [19].

PLA-2 and PLA-4 extr. samples present a somewhat higher zero shear viscosity compared to "neat" internal mixer samples according to Tables 4 and 5. These results suggest that a higher level of degradation was developed during internal mixing preparation due to the higher thermo-mechanical exposition time (13 min.) compared to the REX-Calendered sample (4 min. of residence time), as also observed in SEC characterization.

While the viscosity of the modified samples processed by REX-Calendering was increased at low angular frequencies $\omega$ (i.e. low shear rates), the difference was not as pronounced for values of shear rates near the usual extrusion $\left(\approx 200 \mathrm{~s}^{-1}\right)$ due to the increase of their shear-thinning character (decreased power law index) and the convergence to the same point. This leads to a desirable benefit on the industrial level as their processability is maintained without relevant changes in extrusion conditions. 
The results obtained up to that point suggest that the scaling up of the processing conditions from the internal mixing process to the one-step REX-Calendering process was correctly obtained. Since a onestep processing technique is of interest, samples produced during internal mixing will not be analyzed and only REX-Calendered samples will be considered for further analyses.

Information regarding the melt elasticity can be found by considering the storage modulus $\left(G^{\prime}\right)$ [26]. As shown in Figure 7b, at high angular frequencies, $G^{\prime}$ values tend to converge to a similar point, somewhat higher in the case of the modified samples compared to the unmodified ones. As already observed by Han and Jhon [27], the molecular weight distribution is the governing parameter at high frequency while the influence of the chain structure is minimal. This was also expected for the materials under study and verified by SEC analysis. More specifically, a slight increase in polydispersity index and the appearance of bimodal distributions can be observed (c.f. Table 3).

According to the linear viscoelasticity predictions, the slope of $\log G^{\prime}$ vs. $\log \omega$ is equal to 2 in the terminal regime [28]. PLA-2 extr. and PLA-4 extr. samples present the typical behaviour of linear polymers with the presence of a terminal regime at relatively high frequencies which indicates a fast relaxation process of the chains. However for modified samples, the terminal zone of the storage modulus is broadened and the transition is shifted to lower frequencies, indicating a longer relaxation process of a better cohesive network formation [29]. As already observed by Liu et al. [30], this change of behaviour demonstrates the existence of randomly branched LCB in modified samples. Furthermore, $G^{\prime}$ shows higher values in the case of the modified samples, indicating an increase in the melt elasticity. This latter increase is more pronounced in the sample PLA-2-REX.

Although randomly branched LCB was generated in the modified samples, the exact composition and chain topology is not known. It is believed to be a mix of several components, each one with a different chain topology such as long-chain, star, $H$ or comb-shaped branched structures [31]. Typical spectroscopic methods do not work either in order to determine these structures due to erroneous results quantities. Otherwise, the combination of linear vis- coelasticity and rheology may be a useful way to determine these structures. The phase angle $\delta$ instead of modulus $\left(G^{\prime}(\omega)\right.$ and $\left.G^{\prime \prime}(\omega)\right)$ or viscosity $\left(\left|\eta^{*}(\omega)\right|\right)$ was taken into account to predict the exact topology due to its comparably higher sensitivity to chain structures.

According to the theory of Trinkle and Friedrich [32], the Reduced van Gurp-Palmen-plot (RvGP) is a more transparent way to show the correlation between rheological data with long chain branching features. This plot is a powerful way to characterize the polymer chain structure from small amplitude oscillatory shear experiments, independently of the polymer used, the characteristic elementary relaxation time $\tau_{0}$ or the temperature and tacticity.

As can be seen in Figure 9, both unmodified PLA samples (extr. ones) exhibit the typical behaviour of a linear polymer with a curve reaching a phase angle of $90^{\circ}$ for low $\left|G^{*}\right| / G_{\mathrm{n}}^{0}$ ratios. This corresponds to the lower frequencies oscillatory range of the respective master curve, indicating a viscous behaviour [33].

Trinkle et al. [31] reported that changes in the curve behavior (phase angle $\delta$ lowered or curve flattened) was mainly due to the effect of long chain branching and complex topologies created. According to the RvGP curves of star-polymers (poly(ethane-altpropene)) proposed by Trinkle et al. [31] as well as the study of Lohse et al. [33] for well-defined polymer structures, the RvGP data at hand suggests the formation of asymmetric tree-arm star-branched polymers. PLA-2-REX seems to present longer arm lengths than PLA-4-REX due to the more pronounced bump at $60^{\circ}[31]$.

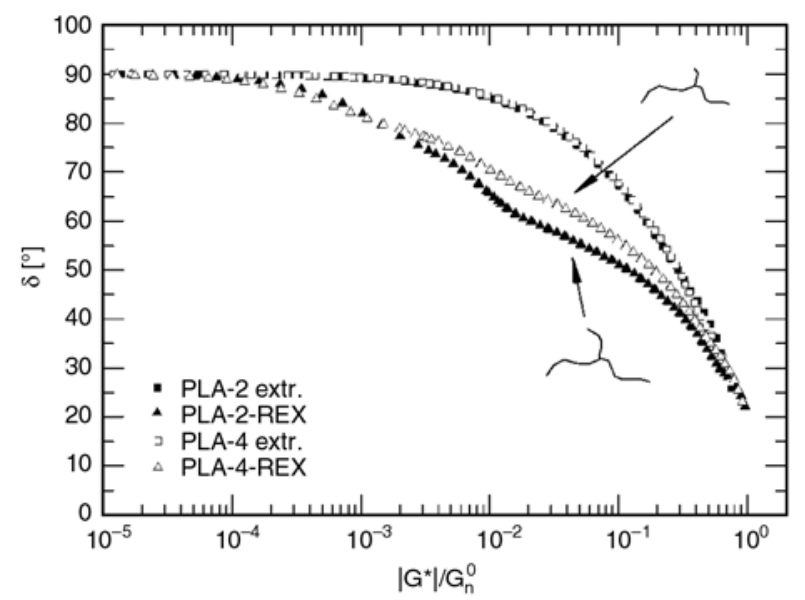

Figure 9. Reduce Van Grup Palmen plot (RvGP) for REXCalendered samples. The two different tree arm star polymers are sketched to show the possible conformation. 
As stated by the simulation performed by Liu et al [30] for PLA modified by a Dicumyl peroxide (DCP) samples and the similarity with Figure 8 for the storage modulus shape as well as Figure 9 for the delta shape, small amounts of asymmetric tree-arm star-branched polymers and linear chains in the modified samples may be expected.

Based on a technique developed by Honerkamp and Weese [16], the weighted relaxation spectrum $\lambda H(\lambda)$ was calculated from the linear relaxation spectrum $H(\lambda)$. It reflects the chain relaxation time distributions for REX-Calendered samples. Those are related to different kinds of chain movements dictated by their topologies.

As can be seen in Figure 10, both unmodified PLA samples (extr. ones) samples exhibit a short-time peak which is attributed to the reptation mechanism. It is the main relaxation process for linear polymers, which is the escape of chains by translation diffusion process along a tube.

Moreover, Figure 10 shows the presence of two and three main relaxation peaks, respectively for PLA4-REX and PLA-2-REX samples. As a consequence, the melt response times increased for these samples. This is possibly due to asymmetric tree-arm star-branched polymer chains generated during the extrusion process. Furthermore, the reptation mechanism is not inhibited due to the large proportion of remaining linear chains. However, it is superseded by primitive path fluctuations and constraint release relaxations which are cumulative effects of the diffusion of the ends of the arms back toward the central star junction [28]. The need to retract an entangled branch is necessary for the backbone relaxation giving rise to an important increase of relaxation times. Wood-Adams and Costeux [34] also

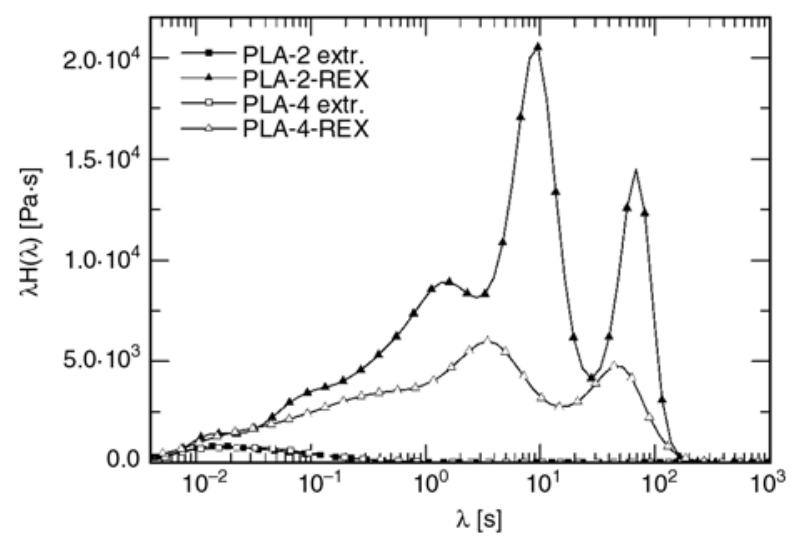

Figure 10. Weighted relaxation spectra $(H(\lambda))$ for REXCalendered samples at $180^{\circ} \mathrm{C}$ observed a bi-modal distribution in the weight relaxation spectrum for long chain branched $\mathrm{PE}$, as well as Dorgan et al. [35] for star PLA samples.

For PLA-2-REX samples, relaxation times are always slightly larger due to longer arm lengths compared to PLA-4-REX. The area under the curve, which is related to the zero-shear viscosity and to the increase of molecular weight, confirms the results previously obtained.

\section{Conclusions}

For both reactive process employed in this work, results suggest a competition between polymer degradation and chain extension as well as chain branching reactions during processing. Internal mixer studies reveal a higher thermal sensitivity of PLA-2 during processing due to its narrower processing window and higher concentration of terminal functional groups compared to PLA-4. However, independently of the mixing process and the processing conditions employed, as a consequence of this more pronounced degradation, PLA-2 presents a higher reactivity towards the SAmfE agent during processing.

SEC together with RDA results suggest a minimized degradation of the polymer in the REX-Calendering process. Considering these assumptions, the rheological characterization reveals a higher modifications degree of the melt rheological behaviour for REX-Calendered samples compared to internal mixer ones.

Even though size exclusion chromatography presents some limitations with branched polymers due to co-elution problems, an increase in the molecular weight was detectable for all modified samples. Regarding the molecular weight distribution, some differences could be appreciated between internal mixer and REX-Calendered samples. In fact, for these latter samples, the bi-modal distribution is less pronounced compared to internal mixer samples, indicating a more homogeneous structure in samples processed by REX-Calendering.

The presence of several curvatures in the shearthinning region of the rheological experiments suggests long chain branching in all modified samples. Differences in the double logarithmic derivative shape versus $\log \omega$ between internal mixer and REXCalendered samples suggest that the molecular modifications induced by the latter processing mode 
increase the relaxation processes due to a better cohesive structure.

Regarding REX-Calendered samples, the terminal zone of $G^{\prime}$ is broadened and shifted to lower frequencies which indicates that the melt elasticity of these samples is increased. In fact, the presence of possible asymmetric tree-arm star-branched polymers considerably increases the chain relaxation time.

\section{Acknowledgements}

The authors would like to thank the MICINN (Spain), the projects financial support MAT2010-19721-C02-01, MAT2010-19721-C02-02 and finally BASF $^{\circledR}$ for kindly supplying chain extender.

\section{References}

[1] Fukushima K., Fina A., Geobaldo F., Venturello A., Camino G.: Properties of poly(lactic acid) nanocomposites based on montmorillonite, sepiolite and zirconium phosphonate. Express Polymer Letters, 6, 914926 (2012).

DOI: $10.3144 /$ expresspolymlett.2012.97

[2] Carrasco F., Gámez-Pérez J., Santana O. O., Maspoch M. L.: Processing of poly(lactic acid)/organomontmorillonite nanocomposites: Microstructure, thermal stability and kinetics of the thermal decomposition. Chemical Engineering Journal, 178, 451-460 (2011).

DOI: $10.1016 /$ j.cej.2011.10.036

[3] Wang Y., Steinhoff B., Brinkmann C., Alig I.: In-line monitoring of the thermal degradation of poly(L-lactic acid) during melt extrusion by UV-vis spectroscopy. Polymer, 495, 1257-1265 (2008).

DOI: 10.1016/j.polymer.2008.01.010

[4] Bhat G. S., Gulgunje P., Desai K.: Development of structure and properties during thermal calendering of polylactic acid (PLA) fiber webs. Express Polymer Letters, 1, 49-56 (2007).

DOI: $10.3144 /$ expresspolymlett.2008.7

[5] Doi Y., Kanesawa Y., Kunioka M., Saito T.: Biodegradation of microbial copolyesters: Poly(3-hydroxybutyrate-co-3-hydroxyvalerate) and poly(3-hydroxybutyrate-co-4-hydroxybutyrate). Macromolecules, 1, 2631 (1990).

DOI: $10.1021 / \mathrm{ma} 00203 \mathrm{a} 006$

[6] Yu H., Huang N., Wang C., Tang Z.: Modeling of poly(L-lactide) thermal degradation: Theoretical prediction of molecular weight and polydispersity index. Journal of Applied Polymer Science, 11, 2557-2562 (2003).

DOI: $10.1002 /$ App.12093

[7] Zhang X., Wyss U. P., Pichora D., Goosen M. F. A.: An investigation of the synthesis and thermal stability of poly(DL-lactide)). Polymer Bulletin, 6, 623-629 (1992). DOI: $\underline{10.1007 / \mathrm{BF} 00297431}$
[8] Signori F., Coltelli M-B., Bronco S.: Thermal degradation of poly(lactic acid) (PLA) and poly(butylene adipate-co-terephthalate) (PBAT) and their blends upon melt processing. Polymer Degradation and Stability, 94, 74-82 (2009). DOI: $10.1016 /$ j.polymdegradstab.2008.10.004

[9] Nishida H., Mori T., Hoshihara S., Fan Y., Shirai Y., Endo T.: Effect of tin on poly(L-lactic acid) pyrolysis. Polymer Degradation and Stability, 81, 515-523 (2003). DOI: 10.1016/S0141-3910(03)00152-6

[10] Raquez J-M., Narayan R., Dubois P.: Recent advances in reactive extrusion processing of biodegradable polymer-based compositions. Macromolecular Materials and Engineering, 293, 447-470 (2008).

DOI: $10.1002 /$ mame.200700395

[11] Corre Y-M., Duchet J., Reignier J., Maazouz A.: Melt strengthening of poly (lactic acid) through reactive extrusion with epoxy-functionalized chains. Rheologica Acta, 50, 613-629 (2011).

DOI: $10.1007 / \mathrm{s} 00397-011-0538-1$

[12] Pilla S., Kim S. G., Auer G. K., Gong S., Park C. B.: Microcellular extrusion-foaming of polylactide with chain-extender. Polymer Engineering and Science, 49, 1653-1660 (2009).

DOI: $10.1002 /$ pen.21385

[13] NatureWorks: PLA polymer 2002D. Technical Papers (2011).

[14] NatureWorks: PLA polymer 4032D. Technical Papers (2011).

[15] BASF: Joncryl ADR-4300. Technical Papers (2011).

[16] Honerkamp J., Weese J.: A nonlinear regularization method for the calculation of relaxation spectra. Rheologica Acta, 32, 65-73 (1993). DOI: $10.1007 / \mathrm{BF} 00396678$

[17] Hansen S.: Estimation of the relaxation spectrum from dynamic experiments using Bayesian analysis and a new regularization constraint. Rheologica Acta, 47, 169-178 (2008). DOI: $10.1007 / \mathrm{s} 00397-007-0225-4$

[18] van Gurp M., Palmen J.: Time-temperature superposition for polymeric blends. in 'Proceedings of the XII ${ }^{\text {th }}$ International Congress on Rheology, Quebec, Canada', 134-135 (1996).

[19] Stadler F. J., Münstedt H.: Numerical description of shear viscosity functions of long-chain branched metallocene-catalyzed polyethylenes. Journal of NonNewtonian Fluid Mechanics, 153, 203 (2008).

DOI: $10.1016 /$ j.jnnfm.2008.05.001

[20] Incarnato L., Scarfato P., Di Maio L., Acierno D.: Structure and rheology of recycled PET modified by reactive extrusion. Polymer, 41, 6825-6831 (2000). DOI: 10.1016/S0032-3861(00)00032-X

[21] Nguyen Q. T., Japon S., Luciani A., Leterrier Y., Månson J-A. E.: Molecular characterization and rheological properties of modified poly(ethylene terephthalate) obtained by reactive extrusion. Polymer Engineering and Science, 8, 1299-1309 (2001).

DOI: $10.1002 /$ pen. 10830 
[22] Bikiaris D. N., Karayannidis G. P.: Chain extension of polyesters PET and PBT with two new diimidodiepoxides. II. Journal of Polymer Science Part A: Polymer Chemistry, 34, 1337-1342 (1996).

DOI: $10.1002 /($ SICI) 1099-0518(199605)34:7<1337:: AID-POLA22>3.0.CO;2-9

[23] Bigg D. M.: Polylactide copolymers: Effect of copolymer ratio and end capping on their properties. Advances in Polymer Technology, 24, 69-82 (2005).

DOI: $10.1002 / A d v .20032$

[24] Zhang L., Zhou J., Yang G., Chen J.: Preparative fractionation of polysaccharides by columns packed with regenerated cellulose gels. Journal of Chromatography A, 816, 131-136 (1998).

DOI: 10.1016/S0021-9673(98)00475-0

[25] Palierne J. F.: Linear rheology of viscoelastic emulsions with interfacial tension. Rheologica Acta, 3, 204-214 (1990).

DOI: $10.1007 / \mathrm{Bf} 01331356$

[26] Park H. E., Dealy J., Münstedt H.: Influence of longchain branching on time-pressure and time-temperature shift factors for polystyrene and polyethylene. Rheologica Acta, 46, 153-159 (2006).

DOI: $10.1007 / \mathrm{s} 00397-006-0116-0$

[27] Han C. D., Jhon M. S.: Correlations of the first normal stress difference with shear stress and of the storage modulus with loss modulus for homopolymers. Journal of Applied Polymer Science, 32, 3809-3840 (1986).

DOI: 10.1002/app.1986.070320302

[28] Dealy J. M., Larson R. G.: Structure and rheology of molten polymers. Hanser, Munich (2006).
[29] Nam G. J., Yoo J. H., Lee J. W.: Effect of long-chain branches of polypropylene on rheological properties and foam-extrusion performances. Journal of Applied Polymer Science, 96, 1793-1800 (2005).

DOI: 10.1002/app.21619

[30] Liu J., Lou L., Yu W., Liao R., Li R., Zhou C.: Long chain branching polylactide: Structures and properties. Polymer, 51, 5186-5197 (2010).

DOI: $10.1016 /$ j.polymer.2010.09.002

[31] Trinkle S., Walter P., Friedrich C.: Van Gurp-Palmen plot II - Classification of long chain branched polymers by their topology. Rheologica Acta, 41, 103-113 (2002).

DOI: $10.1007 / \mathrm{s} 003970200010$

[32] Trinkle S., Friedrich C.: Van Gurp-Palmen-plot: A way to characterize polydispersity of linear polymers. Rheologica Acta, 40, 322-328 (2001). DOI: $10.1007 / \mathrm{s} 003970000137$

[33] Lohse D. J., Milner S. T., Fetters L. J., Xenidou M., Hadjichristidis N., Mendelson R. A., García-Franco C. A., Lyon M. K.: Well-defined, model long chain branched polyethylene. 2. Melt rheological behavior. Macromolecules, 35, 3066-3075 (2002).

DOI: $\underline{10.1021 / \mathrm{Ma} 0117559}$

[34] Wood-Adams P., Costeux S.: Thermorheological behavior of polyethylene: Effects of microstructure and long chain branching. Macromolecules, 34, 6281-6290 (2001). DOI: $10.1021 / \mathrm{ma} 0017034$

[35] Dorgan J. R., Williams J. S., Lewis D. N.: Melt rheology of poly(lactic acid): Entanglement and chain architecture effects. Journal of Rheology, 43, 1141-1155 (1999).

DOI: $10.1122 / 1.551041$ 